Journal of Architectural Research and Development

Review Article

\title{
River Treatment and Measures in Water Conservancy Projects of Small Farmland
}

\author{
Guilan Chen
}

Shanghai Tusguan Engineering Design Consulting Co., Ltd., Shanghai 200000, China

\begin{abstract}
China is country of massive agriculture. Although it has gradually changed from traditional agriculture to modern agriculture in recent years, there are still many problems in the transition. Rivers play an important role in water conservancy projects of farmland. Therefore, full attention should be paid to river management of farmland. This thesis analyzes it and proposes countermeasures for governance.

Keywords: Small farmland; Water conservancy project; River regulation

Publication date: July, 2020

Publication online: 31 July, 2020

*Corresponding author: Guilan Chen, cglyzu@163. com
\end{abstract}

\section{Introduction}

The main purpose of the farmland river engineering is to effectively solve the problem of diverting and draining water in the project area. To Protect the water resources of cultivated land is the foundation of agricultural development and it is related to the motivation of agricultural production. Due to differences in China's agricultural area and regional environment, differences in allocation of water resource are inevitable ${ }^{[1-2]}$. However, due to many constraints, there are many problems in the governance of farmland river engineering in the current water conservancy projects. In view of the current problems, we must adopt a positive attitude to promote the governance of farmland rivers and the modernization of China's agricultural economy, and we should form a relatively complete irrigation and drainage engineering system through the transformation of small farmland water conservancy projects so that "we can irrigate when it is dry out, and drain when it is flooded with water". Finally, we will to achieve the effect of a marked improvement in agricultural production conditions, a marked increase in capacity of comprehensive agricultural production and in the ability to resist natural disasters.

\section{Analysis of water conservancy projects of farmland}

This thesis summarizes the characteristics of water conservancy projects of small farmland by analyzing the current situation of diverting and draining water on Chongming Island.

\subsection{Current situations of farmland drainage}

The entire Chongming Island is a typical large-scale irrigation area with a dense river network. The water for production, living and ecology of the island is introduced from the Yangtze River by the city and county rivers through the culvert gates on the embankment. The water flow of the south tributary of Yangtze River is stable and the water quality is relatively good. The island has formed an overall pattern of "diversion of water from the west to the east and drainage from the south to the north" by considering that the salt tide goes upstream and topographical conditions. The farmland on the island is basically divided into relatively independent small irrigation areas by rivers in county and rivers in town. Pumping stations are used to directly pump water from the rivers in town for irrigation, or the diversion rivers divert water from the rivers in town and then pumping stations are used for irrigation. Therefore, river diversions around the island, rivers in county, and rivers in town have functions of both diversion and drainage. The irrigation and drainage of farmland ditches in small 
irrigation areas are separated, which is conducive to irrigation, drainage, and waterlogging.

The farmland drainage system of Chongming Island is mainly composed of rivers and ditches in town, among which rivers in town have the functions of both diversion and drainage along with the functions of irrigation and drainage of farmland. And ditches have the functions of draining flood on field and controlling underground water level of farmland. The township-level rivers are generally arranged in an east-west direction perpendicular to the county-level rivers, with the spacing about $1000 \mathrm{~m}$, the bottom width of $3.0 \sim 5.0 \mathrm{~m}$, the river bottom elevation of $1.0 \sim 1.5 \mathrm{~m}$, the slope of 1:1.5 $\sim 1: 2.0$, and the distance between the rivers of 80 . $\sim 120 \mathrm{~m}$, the bottom width of about $1.0 \mathrm{~m}$, the ditch bottom elevation of $2.0 \sim 2.5 \mathrm{~m}$, and the side slope of about 1:1 1:1.5. They are basically in line with the requirements of controlling the level of underground water. The ditch and the agricultural canal are arranged alternately, and the width of the field is general $40-60 \mathrm{~m}$. The drainage system of the field is composed of these agricultural canals, ditches and rivers.

\subsection{Characteristics of engineering}

(1) The project construction sites are scattered with a long line, large area, and massive management area.

(2) The project is geographically limited. The project construction is mainly carried out in farmland areas, so the farmland coordination is complicated.

(3) The project is seasonal, and the crop planting season has a greater impact on the project.

(4) Most of the projects are constructed in the fields, but the farmland passages are narrow, and the access of construction equipment is restricted.

(5) Due to the limits of agricultural land, some rivers are small in scale and low in standard.

\section{Problems in river governance in small farmland water conservancy projects}

(1) The awareness of environment protection is gradually increasing

Residents live along most of the township-level rivers, whose traditional living habits have resulted in the direct discharge of domestic sewage into the rivers and the construction of chicken and duck sheds adjacent to the river. They have a great impact on the water quality of the river. In recent years, through improvement projects of rural domestic sewage, along with five-shed treatment and elimination of black and odor, the water quality of the river has been greatly improved. With the improvement of living standards, people pay more and more attention to the water environment of rivers, and the requirements for river improvement are also higher and higher.

(2) Natural disasters

Small farmland water conservancy projects are seriously affected by the natural environment, so river governance must also bear greater natural risks. This kind of natural disaster is reflected in the hydrogeology of the river course, and these environments constitute a lurking danger to the effective implementation of river governance $e^{[3-6]}$. In addition, due to the suddenness and irreversibility of natural risk factors, it is difficult to completely avoid the natural risks faced by river improvement projects. Only specific measures can prevent and control them.

(3) Water pollution of water

In order to maximize their economic benefits, residents will exploit large amounts of non-renewable resources without hesitation by destroying the environment. At the same time, in order to increase the success rate of development, environmental pollution was directly ignored, and factories and civil engineering were built recklessly. Some companies and factories even discharge untreated sewage directly into the river in order to save costs. It not only increases the floating industrial waste into the river, but also pollutes the river. It will lead to hypoxia in water bodies, and many plants are dying due to toxic substances and hypoxia. At the same time, the fish and microorganisms in the river will die because of the loss of food. Therefore, water pollution will not only weaken the self-cleaning ability of the river, but also seriously affect the ecological chain of the river.

(4) Technology of river bank protection needs to be improved

River protection needs to be improved. In recent years, as people's awareness of environmental protection has increased, higher requirements have been placed on river improvement and water environmental protection. However, due to the influence of the traditional concept of market economy, many companies have always focused on improving their economic benefits. Therefore, river protection is still in its preliminary stage, which has had a very negative impact on the overall development of agriculture. In addition, due to the large difference between the surrounding environment and regional geomorphology in the actual 
operation, the advantages of ecological bank protection technology are not fully utilized. Not only does it affect the quality and efficiency of project operation, but also fail to achieve the purpose of river management and protecting the water quality.

\section{Measures for river treatment of farmland water conservancy projects}

(1) Residents' awareness of protection and actions needs to be further improved

The villagers' awareness of river protection will improve by announcement and education. Awareness of supervision and management should also be improved, and the awareness of river environment protection have been continuously improved. Only by urging villagers to consciously participate in the maintenance of the river and jointly protect the river environment can the idea of river protection be deeply rooted in the hearts of the people. And It goes that way in the long run.

(2) Construction management should be strengthened The management of construction projects within the scope of river management needs to be strengthened, and the approval system should also be strictly implemented. The construction of projects within the scope of river management should be supervised to minimize the impact on the river.

(3) Prevention of soil erosion

In addition to supervision and management, prevention and maintenance of river hazards should also be strengthened. Various plants can be planted to increase the diversity of vegetation and various flowers and grasses can be introduced while planting various green trees. In order to promote the healthy development of society and economy, it is necessary to plan vegetation on both sides of the river. In this way, it can ensure the normal use of controlling flood of the river, when the rainstorm occurs. Therefore, the occurrence of soil erosion can be effectively prevented, and the life and property safety of the people can be guaranteed.

(4) River dredging

In accordance with the spirit of the relevant documents, the central and local governments have launched a series of measures, focusing on increasing the construction of farmland water conservancy project (rural water conservancy), as well as focusing on solving and earnestly paying attention to the most concerned, direct and realistic water security and water environment of the people to serve the development of urban and rural areas, accelerate the improvement of people's livelihood, and promote social harmony. Combined with relevant planning, a normalized river regulation mechanism should be established. Dredging of the river channels in the region should be done, ensuring the water storage and water transfer of the river channels, and further improving the selfpurification capacity of the river channels. It is an effective supplement and improvement to the regional river governance.

(5) Structure of river bank protection

The biggest feature of the structure of river bank protection involved in water conservancy projects of small farmland is to combine the needs of surrounding water conservancy projects of farmland and adopt an ecological structure. Chongming Island's research in this area has been continuously developing. From the previous concrete lining structure to the green concrete slope protection structure, to the continuous improvement of materials such as water and soil protection blankets. Its water permeability, soil and water microbial interaction and other properties have been greatly improved. Of course, this is also a longterm research work. Hopefully, materials with better performance can be researched.

(6) Biological treatment

As there are currently no restrictions on the discharge of sewage from rivers, the source of sewage is very complex. The content of nitrogen, phosphorus and other substances in the river increases. Planktonic algae proliferate in large numbers, competing for river survival resources. The stability of the river ecosystem has been severely damaged. Among the various existing treatment methods, the biological treatment method can meet the treatment of river water in a short time and obtain a constant effect, so the use of biological treatment methods should be encouraged. That is to say, a certain number of microbial populations that can inhibit the growth of algae can be put into the river, and the number of planktonic algae can be reduced through the competition between microbes and algae, and the growth of aquatic plants can be promoted at the same time. The ecological balance effectively solves the environmental problems of the river and creates a new dynamic balance.

\section{Conclusion}

In short, as people's awareness of environmental protection continues to increase, ensuring the correct implementation of environmental governance and 
protection is an important development direction of the Ministry of Environmental Protection currently, and it is an important foundation and basic prerequisite for achieving national sustainable development. River governance and water environmental protection are important aspects of environmental governance. River governance is related to the living environment of the villagers, the future development of nearby factories and the ecological balance of the surrounding area. River improvement can greatly improve the irrigation conditions of farmland and activate the sustainable development of local agriculture. It can provide stable river protection, promote the development of new farmland, enhance the ability of agriculture to fight against floods and droughts, and promote stable agricultural production and continuous growth of farmers' income.

However, in the current actual operation process, there is always a certain gap between the operation effect and the expected operation target. Office of river improvement and water quality environmental protection is also under greater pressure. In order to solve the above problems fundamentally. Relevant departments should ensure that the above optimization work is based on the principles of "human beings live in harmony with nature" and "paying attention to species diversity" to lay a good foundation for improving and optimizing the structure of water bodies.

\section{References}

[1] Wang L. River governance issues in small farmland water conservancy projects[J]. Jiangxi Agriculture, 2019(10): 51.

[2] Yuan TJ. Research on river governance and strategy in small farmland water conservancy projects[J]. Building Materials and Decoration, 2018(35): 285.

[3] Han T. Analysis of river treatment and countermeasures in small farmland water conservancy projects[J]. Friends of Farmers to Get Rich, 2018(12): 239.

[4] Chen Q. Countermeasures for river control in small farmland water conservancy projects[J]. Jilin Agriculture, 2018(8): 68.

[5] Han XW. Research on river treatment and countermeasures in small farmland water conservancy projects[J]. Shaanxi Water Resources, 2016(S1): 182-184.

[6] Guo GD. Discussion on measures for urban black and smelly river treatment $[\mathrm{J}]$. Urban Construction Theoretical Research (Electronic Edition), 2020(18): 127-128 